\title{
Paisaje cultural y revisitación geográfica. El lago de Pátzcuaro, México
}

\author{
Cultural Landscape and a Geographic Revisiting \\ of Patzcuaro Lake, Mexico
}

Andrea Naranjo Cruz* y Pedro S. Urquijo Torres**

\section{RESUMEN}

Mediante la técnica de revisitación geográfica, se realiza un anáPalabras clave: lisis comparado pasado-presente a través de hitos topográficos revisitación en el paisaje del lago de Pátzcuaro, México. Se recurre al uso de fotografías históricas y contemporáneas, con el fin de contrigeográfica, buir a la comprensión visual y didáctica del paisaje desde una perspectiva culturalista. El estudio de caso resulta más que pertinente para el ejercicio. En la década de 1930, estimulado por paisaje cultural, fotografías, trabajo de campo. proyectos gubernamentales, el lago se convirtió en uno de los principales destinos turísticos nacionales, en los que se promovía específicamente su calidad escénica. En el entorno lacustre se erigieron infraestructuras para la valoración visual del paisaje (miradores, muelles o monumentos). Sin embargo, con el paso de las décadas, el costumbrismo natural y rural de los inicios de la política turística se redireccionó hacia los destinos de playa, y la economía de la región se transformó. El caso brinda así elementos históricos para un ejercicio de revisitación comparativa historia-actualidad. Como resultados, el enfoque de paisaje y la metodología aplicada permiten una aproximación directa al entorno, reconociendo indicadores visuales de cambio cultural de una manera relativamente sencilla, y permite una revaloración

Mexicana. Licenciada en Ciencias Ambientales, Universidad Nacional Autónoma de México (UNAM). Escuela Nacional de Estudios Superiores Unidad Morelia (UNAM). E-mail: andreanaranjo.mexico@gmail.com

" Mexicano. Doctor en Geografía, Universidad Nacional Autónoma de México (UNAM). Investigador Titular del Centro de Investigaciones en Geografía Ambiental (CIGA-UNAM).E-mail: psurquijo@ciga.unam.mx

Esta investigación se desarrolló como parte de las actividades profesionales para titulación de Andrea Naranjo Cruz, en el marco del proyecto PAPIIT IA300120, dirigido por Pedro S. Urquijo Torres. 
didáctica de la observación geográfica y los recorridos en el trabajo de campo.

\begin{abstract}
Using the geographic revisiting technique, this paper performs a comparative past-present analysis through topographic markers along the landscape of the Patzcuaro Lake in Mexico. Historical and contemporary photographs are used to contribute to the visual and didactic understanding of the landscape from a culturalist perspective. The case study appears to be highly pertinent to this exercise. In the 1990s, and driven by government projects, the lake became one of the top national tourist destinations, specifically promoting its great scenery. Around the lake, infrastructure was constructed in order to better appreciate the landscape (lookout points, piers and monuments). However, over the years, tourism policy moved from highlighting natural and rural folk traditions to more beach destinations, and the region's economy was transformed. Therefore, this case offers historical elements for a comparative revisiting of history-contemporary times. As a result, the landscape approach and methodology applied allow for a direct evaluation of the environment, recognizing relatively simple visual indicators of cultural change, and allowing for a didactic revaluation of geographic observation and on-site walkthroughs.
\end{abstract}

Keywords: geographic revisiting, cultural landscape, photography, field work. 
Este artículo se propone contribuir a la comprensión del análisis de paisaje, desde un enfoque cultural, valorando la pertinencia del método de revisitación geográfica o geografía repetida - revisited geography, repeat geography o going back, en inglés-. Para ello, se recurre a las particularidades geográficas del caso del lago de Pátzcuaro, Estado de Michoacán, en el centro-occidente de México, pues se trata de un paisaje históricamente distinguido por su calidad escénica y su promoción visual.

En los últimos años, la metodología de la revisitación geográfica ha sido abordada en dos sentidos principalmente. El primero, orientado hacia el análisis historiográfico, alude al ejercicio de reexaminación de una investigación específica, publicada con ciertos años de anterioridad, valorando posibles aportes conceptuales y aplicados, así como los aciertos y desaciertos del procedimiento analítico por parte del o los autores originales (González-Jácome, 2005; Rose-Redwood, 2008; Laylander, 2016). En un segundo sentido, la revisitación geográfica se entiende como el retorno a un lugar que haya sido estudiado décadas atrás, aplicando el mismo procedimiento metodológico o reutilizando los insumos generados por el o los investigadores antecesores: fotografías, mapas, informes, diario de campo (Mathewson, 2010). Ello con el fin de apreciar las transformaciones espaciotemporales de los paisajes in situ (Works y Hadley, 2000; Walker y Leib, 2002; Brady, 2009; Lira et al., 2019). En el presente artículo se aborda este último procedimiento.

El estudio de caso corresponde al lago de Pátzcuaro, Estado de Michoacán, en el centro-occidente mexicano. El cuerpo lacustre, unidad físico-geográfica que le otorga sentido identitario al paisaje, tiene una extensión cercana a los 126 kilómetros cuadrados y forma parte de una cuenca - con el mismo nombre, Pátzcuaro- localizada en el cinturón serrano del Eje Volcánico Transversal, a una altura cercana a los 2.040 $\mathrm{msnm}$. Jurisdiccionalmente, el lago abarca porciones de cuatro entidades municipales: Quiroga, Erongarícuaro, Tzintzuntzan y Pátzcuaro. En su interior se localizan siete islotes: Janitzio, Yunuen, Pacanda, Tecuena y tres islas conocidas como Urandenes. Jarácuaro dejó su connotación insular en las últimas cuatro décadas del siglo XX, debido al proceso de desecación acelerada del cuerpo lacustre. El lago no cuenta con grandes afluentes de agua, por lo que se abastece solo de los ma- 
nantiales que se encuentran en el borde sur y de las lluvias que caen en temporada - de precipitación moderada-, entre los meses de mayo y octubre. Las cumbres montañosas que circundan el paisaje lacustre son origen extrusivo y están moderadamente escarpadas, correspondiendo la máxima elevación al cerro Tzirate, aproximadamente a los $3.300 \mathrm{msnm}$. El clima corresponde al templado subhúmedo, con precipitaciones concentradas entre los meses de mayo y octubre. En cuanto a las cubiertas vegetales, predominan los bosques de coníferas, los de encino y los mixtos, así como algunas comunidades secundarias (Rzedowski et al., 2014) (Figura $\mathrm{N}^{\circ} 1$ ).



Figura $N^{\circ} 1$. Localización del lago de Pátzcuaro, Michoacán, México Fuente: Elaboración propia.

El paisaje del lago de Pátzcuaro ha sido una imagen recurrente para la promoción turística oficial desde la década de 1930; un hito geográfico reconocible tanto para los pobladores locales de la región, como para los visitantes nacionales. Postales, guías turísticas, murales, pinturas y películas han utilizado vistazos del lugar, desde entonces y hasta la fecha. Para los gobiernos posrevolucionarios, encabezados por Lázaro Cárdenas del Río, como gobernador de Michoacán, primero (1928-1930), y como presidente de la República, después (1934-1940), Pátzcuaro era un modelo icónico de un paisaje mexicano que podría 
proyectarse a través de la naciente estrategia turística-económica: un pedazo de México en el que se transitaba entre el pintoresco costumbrismo rural decimonónico (Figura $\mathrm{N}^{\circ} 2$ ) y la grandeza de la modernidad posrevolucionaria (Jolly, 2015 y 2018).

Desde el punto de vista de la tradición, el lago y sus riberas han sido un destino históricamente importante para la conmemoración del Día de los Muertos. Se trata de una fecha solemne y de profundo raigambre en el calendario nacional. La noche del primero al segundo día de noviembre, en diversas partes del país, se espera ritualmente el retorno de los muertos, quienes, en espíritu y por una noche, conviven con los vivos. Las casas y las tumbas en los cementerios se adornan para la ocasión y se preparan los alimentos y bebidas preferidos del difunto. $\mathrm{Si}$ bien se trata de una fecha conmemorativa en todo el país, en la región del lago de Pátzcuaro se encuentran lugares considerados epicentros históricos de la celebración: la isla de Janitzio, el cementerio de Tzintzuntzan o el pueblo de Santa Fe de la Laguna, por mencionar los más recurrentes en los alrededores del cuerpo lacustre. De esta manera, a lo largo del siglo XX, la promoción del calendario ritual vinculado al Día de los Muertos y la política turística que promovía el paisaje transitorio del costumbrismo al modernismo, fueron detonantes de los cambios visuales en el lago de Pátzcuaro.

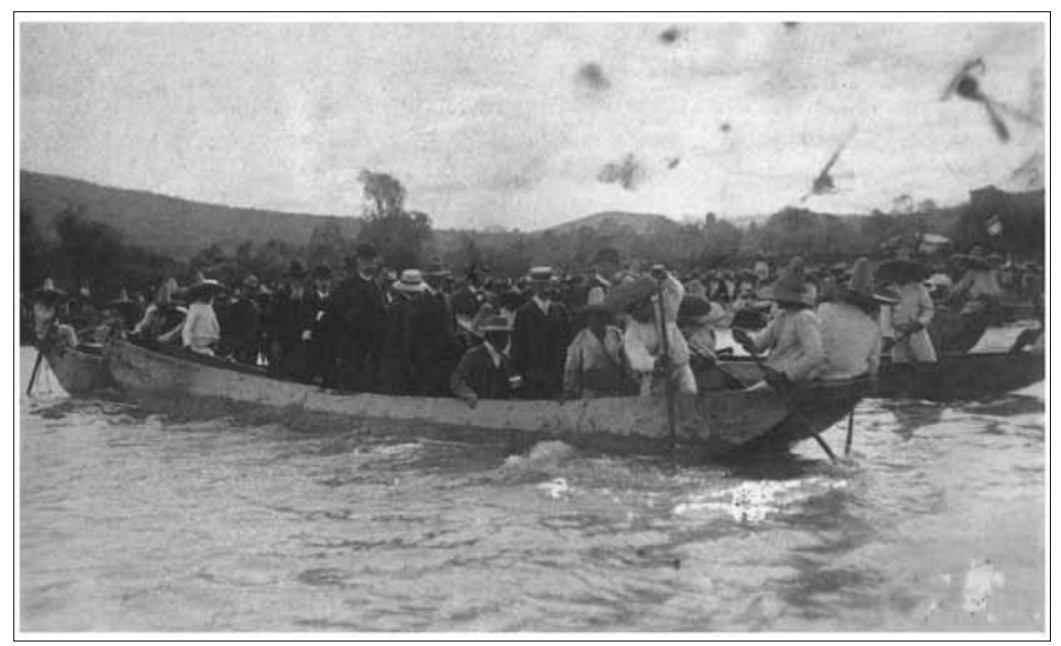

Figura $N^{\circ} 2$. Embarcación de pasajeros en Pátzcuaro, c1900

Fuente: Archivo Gerardo Sánchez Díaz, Instituto de Investigaciones Históricas, Universidad Michoacana de San Nicolás de Hidalgo (IIH-UMSNH). 
Con este contexto histórico, se impulsaron desde las esferas gubernamentales diversos proyectos culturales y de infraestructura para la industria del turismo, tales como el levantamiento de esculturas públicas, miradores estratégicos para la apreciación visual del lago, la restauración de arquitecturas coloniales, apertura de sitios arqueológicos, inauguración de museos y una biblioteca, entre otros. El paisaje lacustre se diseñó así con íconos culturales oficiales, como lo estatua monumental del héroe de la Independencia José María Morelos, justo en la cumbre central de la isla de Janitzio - visible desde cualquier punto del entorno lacustre-, en una atrevida emulación de la Estatua de la Libertad de New York (Urquijo, 2020). Otros íconos que se convirtieron en una constante fueron el uso escenográfico de grandes redes de pesca en forma de alas de mariposa, la proliferación icónica del pez blanco (Chirostoma estor) - entonces abundante en el lago- y la insistencia visual a la vocación forestal vinculada a los recursos forestales de las montañas circundantes. Dichas imágenes del paisaje cultural llevaban también una forma de mirar; una estrategia inducida en la escala de poder gubernamental, pro de la nación y el nacionalismo (Jolly, 2015 y 2018).

Debe reconocerse, por otro lado, que el enfoque de la geografía cultural es un recurso epistemológico apropiado para la presente investigación. La perspectiva geográfico-cultural pone el énfasis analítico en las concepciones o expresiones con las que distintas sociedades transforman sus paisajes, de acuerdo con sus particulares formas de conocimiento, brindando particular importancia a los aspectos subjetivos, los cuales a menudo escapan a los datos convencionales de información geográfica: fisiográficos, demográficos, económicos (FernándezChristlieb, 2006). Es decir, si bien es cierto que el paisaje alude a una materialidad geográfica - física y concreta-, para una comprensión integral y cultural del concepto es necesario asumir que también esa materialidad implica una recepción sensible de quienes se desenvuelven en el lugar y transforman el entorno.

El enfoque cultural permite la comprensión de las "marcas" o "trazos" tangibles e intangibles en el paisaje, los cuales actúan como estructurantes de los discursos de identidad y de imaginarios con referentes en el entorno, tratando de privilegiar la perspectiva de quienes viven en el lugar. Por ello, en el ejercicio geográfico-cultural, el recono- 
cimiento de las valoraciones sensibles, éticas o estéticas, que realizan las personas que viven cotidianamente sus lugares es fundamental. En este sentido, las imágenes históricamente capturadas es una manera básica de aproximarse a ellas. Los rasgos culturales en el paisaje contribuyen a la formulación de una memoria colectiva o de la construcción de imaginarios, con referentes en los hitos topográficos o geosímbolos paisajísticos. El estudio de los paisajes, bajo esta óptica, permite una mejor comprensión de las agencias que definen a la historia local, el arraigo, la territorialidad o el sentido de lugar (Massey, 1996; Tuan, 2001; Lindón, 2015).

Los paisajes adquieren sentido colectivo a través de las representaciones que se formulan a partir de la memoria sociabilizada. En otras palabras, es una manera en la que los referentes culturales del pasado se hacen presentes. Por tanto, es el aquí y el ahora el que define o redefine lo que fue. Este tipo de historia, como construcción colectiva y cotidiana, atiende los intereses actuales de quienes la proyectan y se conecta con el imaginario social contemporáneo (Sarlo, 2006). En la medida que es una memoria que muestra muy marcadamente un nosotros ante un otro visitante - como sucede en un lugar estrechamente vinculado a la actividad turística-, esa memoria colectiva también atiende a un público al cual orientarse y, con ello, se patrimonializa. En el paisaje, este discurso identitario y patrimonial se define, se marca y se proyecta in situ mediante imágenes arquetípicas e íconos topográficos que el foráneo debe aprender a reconocer.

Con todo lo anterior, puede considerarse que con este tipo de estudios se contribuye a la comprensión de los paisajes como lugares profundamente humanizados, cargados de sentidos y valores locales. Asimismo, se estudian y registran experiencias y emociones históricas vinculadas al lugar, que revelan expectativas sociales cambiantes en torno a la naturaleza (Meyer y Youngs, 2018). En este sentido, el método de revisitación geográfica mediante el uso de fotografías, es una forma directa y aplicada de aproximarse al paisaje cultural, que fomenta una mirada analítica y estimula el trabajo de campo como experiencias primarias de didáctica e investigación.

El artículo se estructura de la siguiente manera. En un primer apartado, se argumenta respecto de la pertinencia de la revisitación geográfica del paisaje cultural, tratando de señalar algunas experiencias 
y derroteros. Posteriormente, se explica el proceso metodológico del estudio en cuestión. Finalmente, se muestran los resultados de la revisitación en el paisaje, valiéndose de fotografías comparadas y sus descripciones, y se exponen algunas conclusiones respecto del método.

\section{La revisitación geográfica como revaloración de la mirada en trabajo de campo}

Como se ha señalado, la revisitación geográfica es una estrategia de indagación comparativa, que permite cotejar los cambios geográficos o ambientales ocurridos en los paisajes, revalorando la información elaborada previamente y contrastándola con el presente. Este método relativamente sencillo cobra particular importancia en el contexto actual de los paisajes y sus aceleradas transformaciones: la expansión urbana, el extractivismo, el turismo expansivo, la degradación de suelos y cubiertas vegetales, por mencionar algunos ejemplos.

En el presente ejercicio de revisitación se recurre específicamente al uso de imágenes fotográficas. El contraste visual de fotografías históricas con imágenes actuales es una estrategia recurrente, tanto en la investigación como en la didáctica de la geografía y las ciencias ambientales (Butler, 1994; Brady, 2009; Bayers, 2017). En este sentido, suele ponderarse el valor escénico del paisaje - sus elementos estéticos-, que en cierta medida están estrechamente relacionados con una interpretación cultural de abundancia ecológica o rural, o bien de majestuosidad arquitectónica o urbanista (Barrasa, 2013). En específico, la comparación fotográfica entre el antes y el después en el paisaje coadyuva, de manera directa y sencilla, en la valoración de las diferencias históricas y cambios geográficos en el lugar mismo, lo que resulta a la vez en una revaloración didáctica del trabajo de campo.

La revisitación geográfica, a través del uso de fotografías comparadas, ha cobrado importancia sobre todo en el estudio de los paisajes categorizados como de patrimonio ambiental, histórico, cultural o turístico, pues pone de realce la experiencia visual de los lugareños y foráneos en sus esfuerzos por establecer referentes a través de hitos topográficos (Urry, 1990; Rakic y Chambers, 2012; Novo et al., 2013; Alvarado-Sizzo y López-López, 2018). Las imágenes aportan una memoria visual de los paisajes, tanto de los aspectos físicos como de los humanos, por lo que se vuelven un material documental más que per- 
tinente. El análisis comparativo entre las fotografías de paisaje pasadopresente puede proporcionar información valiosa, tanto en los usos del terreno como en las trasformaciones de las cubiertas vegetales, y en ocasiones brindan algunas pistas de la ocurrencia o ubicación de los cambios geográficos o ambientales (Walker y Leib, 2002). Desde luego, la revisitación no puede limitarse al análisis contrastante de fotografías, pues se requiere que la información visual extraída de las imágenes se interprete o verifique en relación con otras fuentes de información, que permitan comprender el contexto en el que fueron capturadas: documentación bibliográfica y documental, mapas o libretas de campo, por mencionar algunos ejemplos.

Es importante señalar algunas experiencias de revisitación geográfica mediante el uso de fotografías comparadas, a manera de estado de la cuestión, que permitan reconocer de manera general la pertinencia del método. En concreto, se pone énfasis en los estudios realizados en la misma región en la que se encuentra el lago de Pátzcuaro (Michoacán). Works y Hadley (2000), por ejemplo, recurrieron a la revisitación aprovechando las fotografías de paisaje tomadas por el geógrafo norteamericano Robert West a mediados del siglo pasado, en la Sierra Purépecha de Michoacán, México (West, 1948). West fue uno de los estudiantes directos del distinguido geógrafo estadounidense Carl O. Sauer, fundador de la tradición conocida como Escuela de Berkeley, e impulsor del enfoque de la geografía cultural y los estudios históricos de paisaje (Urquijo et al., 2020). El ejercicio realizado por Works y Hadley consistió en fotografiar los mismos lugares que capturó West, ubicando la cámara en misma posición. Esta estrategia visual permitió observar que una parte del bosque no presentaba una reducción significativa, a pesar del tiempo transcurrido. Incluso, en algunas de sus fotografías llegaron a notar un aumento de la cubierta vegetal. Su conclusión es que, a pesar de la histórica actividad forestal en la región, hay también una experiencia de manejo adecuada.

Bass y Brady (2011) repitieron el estudio realizado por el geógrafo Dan Stanislawski en Michoacán a mediados del siglo XX, quien, al igual que Robert West, fue estudiante de Carl O. Sauer. Stanislawski se interesó por el estudio de la configuración urbana y territorial -la anatomía geográfica, en sus propios términos- de once pueblos en la región michoacana (Stanislawski, 1950). Bass y Brady reutilizaron sus 
mapas y fotografías de tres de las once localidades para realizar la revisita: Buena Vista, Ario de Rosales y Erongarícuaro. Su estudio permitió observar el cambio acelerado en los usos del suelo y una lenta transformación y crecimiento del área urbana.

Lira y colaboradores (2019) revisitaron tres localidades de Michoacán siguiendo el mismo trabajo de Dan Stanislawski: Ario de Rosales, Tacámbaro y Purépero. Se trataba de pueblos caracterizados por dinámicas rurales vinculadas al cultivo del maíz y el manejo forestal, principalmente. En la revisitación, Lira y colaboradores utilizaron tanto las fotografías como los mapas que Stanislawski elaboró en su propia investigación. La investigación mostró cómo, en un lapso mayor a cincuenta años, las dinámicas sociales, económicas y culturales de las localidades se encaminaron hacia el comercio en sector terciario - venta de ropa china, artículos de plástico y telefonía celular-y los cultivos transitaron abrumadoramente a los huertos de aguacate.

\section{Procedimiento metodológico}

Para la elaboración de la revisitación geográfica procedimos a una búsqueda inicial de fotografías históricas del paisaje lacustre. Revisamos, principalmente, la Fototeca del Instituto Nacional de Antropología e Historia (INAH) y la Colección Dr. Gerardo Sánchez Díaz, del Archivo Histórico Fotográfico del Instituto de Investigaciones Históricas de la Universidad Michoacana (IIH-UMSNH). El corte temporal lo establecimos desde la década de 1920 y hasta 1950, cuando la popularidad del lago, como ícono turístico del paisaje mexicano, comenzó a decaer - a partir de entonces se dio un mayor impulso al turismo de playa, cuyo destino emblemático fue Acapulco-. Para acotar la revisión de las imágenes, seleccionamos aquellas que mostraran elementos que pudieran rastrearse visualmente en campo, tales como formas específicas del relieve, islas, monumentos, arquitecturas o muelles. El siguiente criterio se estableció con base en aquellas fotografías que pudieran mostrar cambios significativos en el paisaje cultural.

Del total de fotos analizas, hemos seleccionado seis para presentar en este artículo, basándonos en su representatividad paisajística. Las fotos históricas las contrastamos con tomas contemporáneas, ubican- 
do la misma posición. El uso de cámaras digitales, en la actualidad, nos permite la comparación inmediata y la repetición constante hasta encontrar los ángulos y posiciones adecuadas. Las visitas de campo se realizaron entre los meses de mayo y noviembre de 2019, tratando de obtener con ellas diferentes intensidades lumínicas y el cambio visible en las cubiertas vegetales, de acuerdo con diferentes momentos del año y con la temporada de lluvias y secas. Las tomas implicaban también la toma de puntos GPS para la posterior elaboración de mapas de ubicación (Tabla $\mathrm{N}^{\circ} 1$ ).

Tabla $\mathrm{N}^{\circ} 1$

Esquema de los pasos metodológicos para la revisitación

\begin{tabular}{|c|c|}
\hline Pasos metodológicos & Caso lago de Pátzcuaro \\
\hline $\begin{array}{l}\text { Trabajo de archivo y } \\
\text { documental. Búsqueda } \\
\text { y selección de } \\
\text { fotografías históricas }\end{array}$ & $\begin{array}{l}\text { a) Se revisaron los catálogos de la Fototeca del } \\
\text { Instituto Nacional de Antropología e Historia } \\
\text { (INAH) y de la Colección Gerardo Sánchez } \\
\text { Díaz del Archivo Histórico de IIH-UMSNH. } \\
\text { b) Se seleccionaron fotografías que tuvieran } \\
\text { elementos visuales susceptibles de rastrearse } \\
\text { en campo. } \\
\text { c) Se acotó la temporalidad de las fotografías } \\
\text { (1920-1950), con base en el contexto de } \\
\text { promoción turística nacional del lugar y } \\
\text { hasta antes del cambio político en la materia, } \\
\text { cuando se redireccionaron los recursos } \\
\text { hacia destinos de playa para el turismo } \\
\text { internacional. }\end{array}$ \\
\hline $\begin{array}{l}\text { Trabajo de campo. } \\
\text { Revisitación geográfica }\end{array}$ & $\begin{array}{l}\text { a) Con las fotografías históricas impresas, se } \\
\text { ubicaron in situ los lugares en las que fueron } \\
\text { capturadas en el pasado. } \\
\text { b) El uso de cámaras digitales permitió la } \\
\text { comparación inmediata y la repetición } \\
\text { constante hasta la obtención de los ángulos } \\
\text { adecuados. } \\
\text { c) La temporalidad de las visitas a campo varió } \\
\text { para obtener distintas intensidades lumínicas } \\
\text { y cambios en las cubiertas vegetales, de } \\
\text { acuerdo con los diferentes momentos del año. } \\
\text { d) Los puntos en los que se realizaron las } \\
\text { fotografías se marcaron con el uso de GPS, } \\
\text { con el objetivo de elaborar cartografía de } \\
\text { ubicación. }\end{array}$ \\
\hline
\end{tabular}

Fuente: Elaboración propia. 


\section{Revisitando el paisaje en el lago de Pátzcuaro}

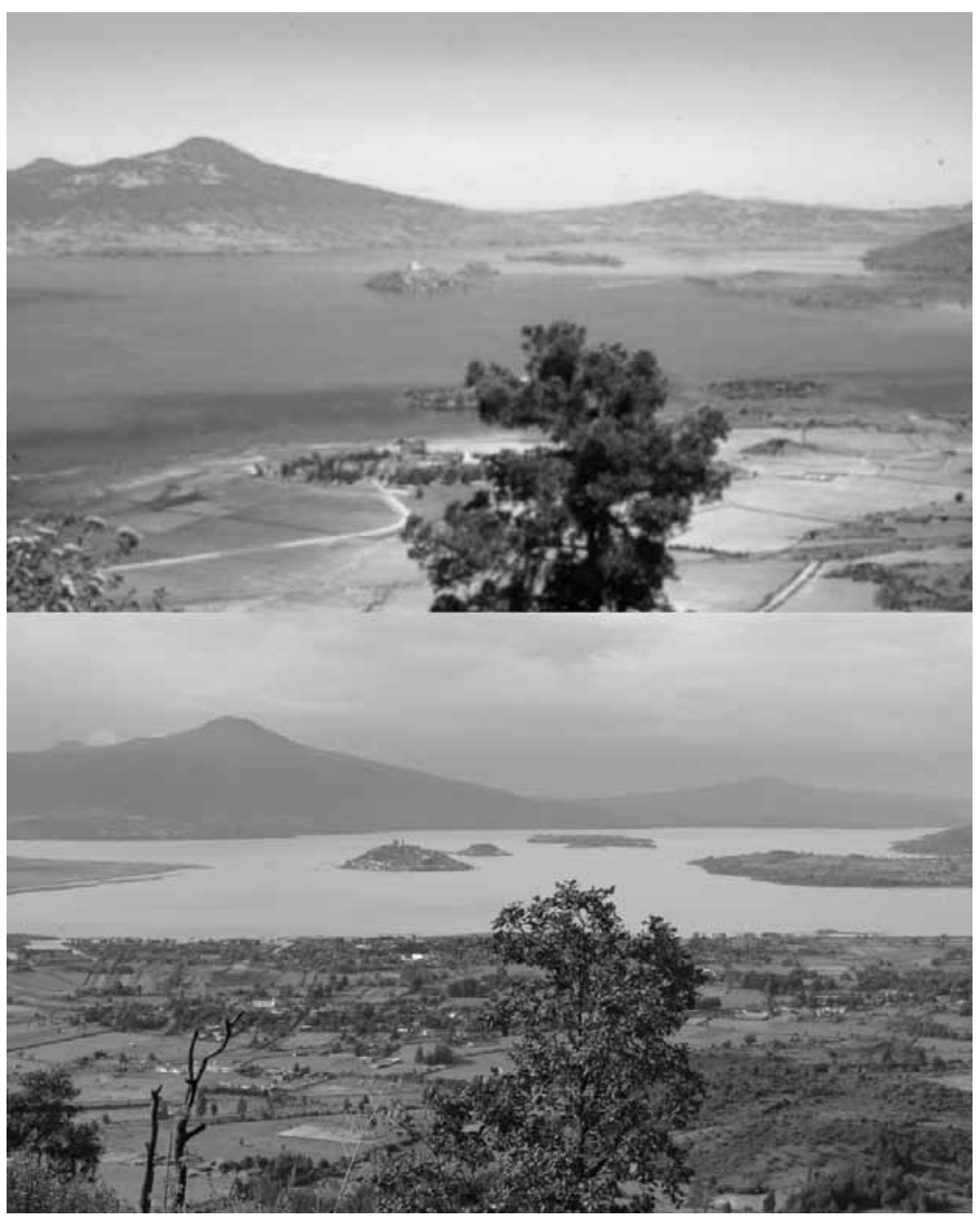

Figuras $N^{\circ} 3$ y $N^{\circ} 4$. Vistas del lago de Pátzcuaro desde el mirador El Estribo

Fuentes: Panorámica de Peter Smithers c1950, Fototeca INAH (Superior); fotografía propia, 2019 (inferior).

Las fotografías de las figuras $\mathrm{N}^{\circ} 3$ y $\mathrm{N}^{\circ} 4$ fueron tomadas desde el mirador del cerro El Estribo, localizado en la zona suroeste del lago y a unos 5 kilómetros del centro de la ciudad de Pátzcuaro. El mirador data de 1936 y forma parte de la infraestructura de promoción turística impulsada por el gobierno nacional de Lázaro Cárdenas (19341940). En ambas imágenes aparece al centro la isla de Janitzio, cuyo 
elemento más evidente es la estatua del héroe de la Independencia José María Morelos y Pavón, justo en la cumbre del cerro de la isla. La estatua también forma parte de la infraestructura de promoción turística y cultural de la década de los treinta. A la izquierda de Janitzio, se aprecian las islas de Tecuena, que significa "miel buena" en lengua purépecha, y Yunuen, "media luna”. En la imagen histórica (Figura $\mathrm{N}^{\circ} 3$ ), en el fondo, en la extrema izquierda, se observa la localidad de Erongarícuaro "lugar de espera", y el cerro El Sandío, en la extrema derecha. En la porción sur del lago, muy cerca de tierra firme y a la derecha del observador, se pueden apreciar las islas Urandenes, "Bateas", que hasta mediados del siglo pasado eran las principales poblaciones para la reproducción del pescado blanco. En tierra firme se visualizan unos pequeños poblados: Tzentzéguaro, "lugar donde suena", y Huecorio "caída de lo alto", además de campos de cultivos y algunos caminos. En la llanura, la vía más notable es la carretera Pátzcuaro-Chupícuaro, "lugar de cielo azul".

La comparación entre la fotografía histórica (Figura $N^{\circ} 3$ ) y la contemporánea (Figura $\mathrm{N}^{\circ} 4$ ), muestra un decremento significativo del nivel de agua del lago, debido a la sobrecarga de nutrientes y al proceso de azolvamiento que lo han impactado de manera significativa. De esta forma, las islas Urandenes se agregaron a la superficie terrestre, perdiendo su connotación isleña y adquiriendo ahora la condición de humedales. Los canales, en las orillas del lago de la fotografía histórica (Figura $\mathrm{N}^{\circ} 3$ ), han desaparecido y proliferan los caminos y cultivos. Los poblados rivereños muestran un notable crecimiento y la isla central de Janitzio está totalmente urbanizada. La fotografía contemporánea corresponde a la temporada de lluvias (entre abril y septiembre), por lo que se justifica el verdor y lo frondoso de las cubiertas vegetales. 


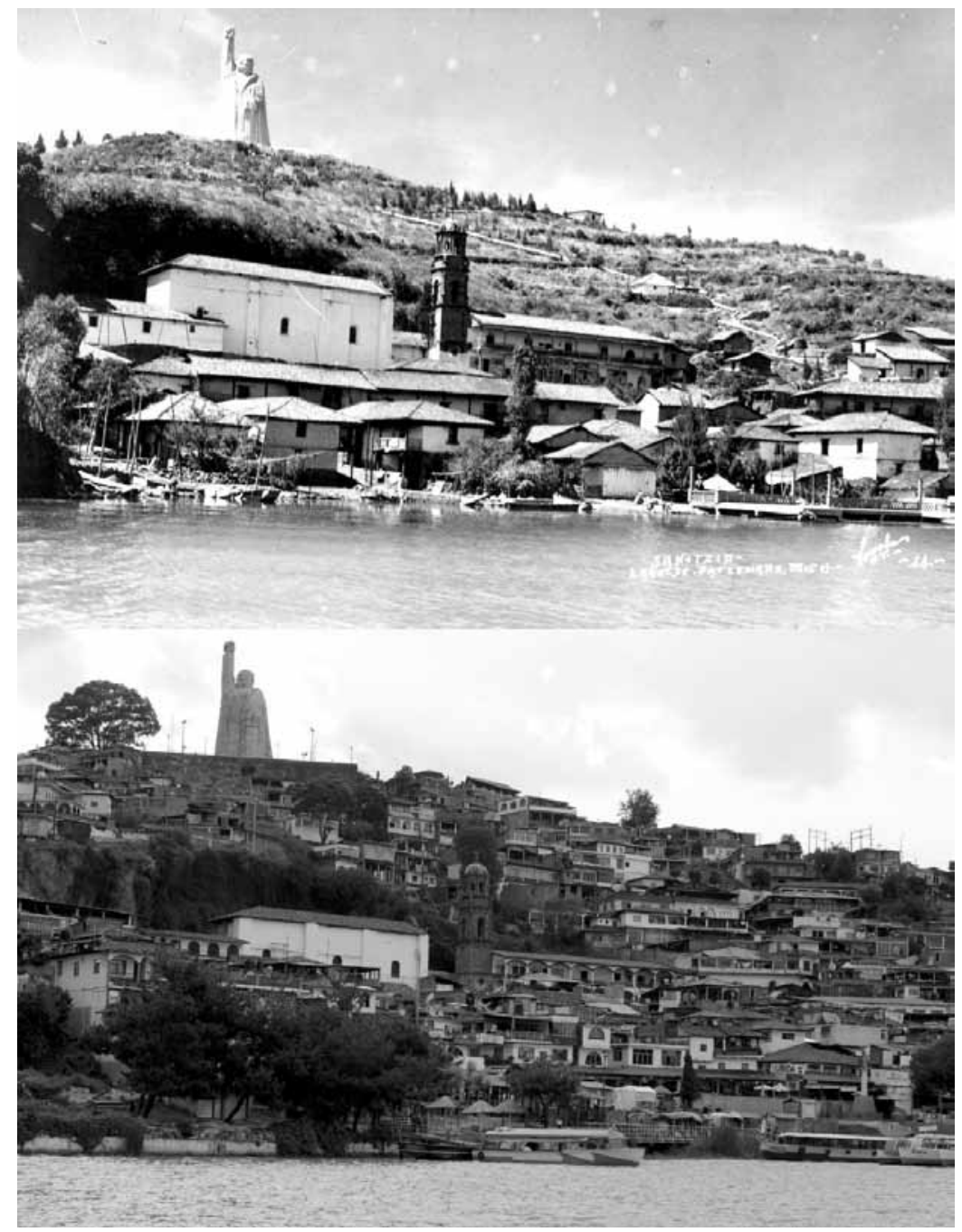

Figuras $N^{\circ} 5 y N^{\circ} 6$. Estatua de Morelos en la isla Janitzio

Fuentes: Fotógrafo Zavala ca1940, colección Gerardo Sánchez Díaz (IIH-UMSNH) (superior). Fotografía propia, 2019 (inferior).

Las fotografías en las figuras $\mathrm{N}^{\circ} 5$ y $\mathrm{N}^{\circ} 6$ fueron tomadas desde embarcaciones en el lago de Pátzcuaro, calculando una distancia, respecto del islote de Janitzio, de unos 500 metros aproximadamente. En la imagen histórica (Figura $\mathrm{N}^{\circ} 5$ ), en la parte más alta de la localidad, se aprecia la estatua de Morelos, lo que indica que la foto debió ser posterior a 1936, fecha de su inauguración, tras cinco años 
de construcción. De manera descendiente a la posición del monumento, en la ladera y hacia el lado derecho de la imagen, se observa el camino que conecta la parte inferior de Janitzio, donde se asienta el pueblo, con la estatua de Morelos. A ambos lados del camino se observa algo de vegetación y los vestigios de terrazas agrícolas. Estas últimas eran una forma tradicional de manejo, una estrategia que permitía el aprovechamiento de las aguas de lluvias de temporal y su escurrimiento natural, utilizando las laderas y el establecimiento de parcelas escalonadas. En la parte baja del islote, de izquierda a derecha, se visualizan las redes de pesca colgadas en los exteriores de las viviendas, los edificios de la población y, en el extremo derecho, el muelle. En la playa hay embarcaciones atrancadas. Una arquitectura notoria en el poblado es la capilla de San Jerónimo, erigida en el siglo XIX, cuya torre es un elemento clave para realizar la revisitación de la imagen a partir de la posición más adecuada para capturar la foto contemporánea.

Respecto de las imágenes histórica y contemporánea (Figura $\mathrm{N}^{\circ} 6$ ), se puede apreciar el crecimiento de la mancha urbana en el islote de Janitzio. El área de cultivo ha desaparecido y el uso de suelo es totalmente habitacional hasta la cúspide. En la imagen, la vegetación se reduce a unos cuantos árboles dispersos. La forma arquitectónica de las casas muestra cierta improvisación constructiva, tratando de aprovechar las características del relieve. El muelle y la línea de playa, que antes albergaban pequeñas embarcaciones pesqueras, ahora presentan exclusivamente barcos amplios para el uso turístico. Se aprecia también, en la costa, carpas y sombrillas para los pequeños negocios de atención a los visitantes. Todo ello explica visualmente un cambio radical en la vocación de Janitzio, que pasó, en unas cuantas décadas, de una localidad pesquera y agrícola a una población dedicada fundamentalmente al turismo. En el lago, bordeando el muelle, se observa una capa de lirios acuáticos, indicador de contaminación en el agua. De ahí que el lago se encuentre dentro del rango de eutrófico a hipereutrófico, de acuerdo con los valores de clorofila lacustre, mostrando un tono verdoso obscuro, con altos niveles de fósforo disuelto (AlonsoEguía y Vargas, 2014). 


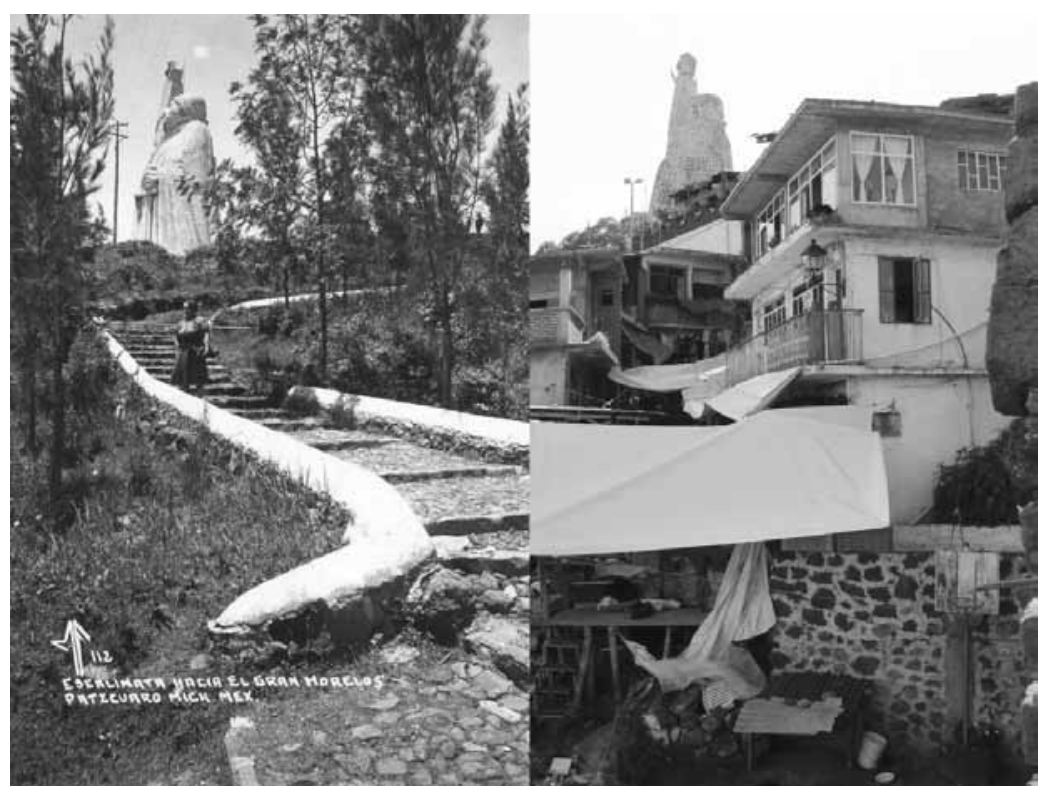

Figuras $N^{\circ} 7$ y $N^{\circ} 8$. Escalinatas hacia la estatua de Morelos

Fuentes: Colección Gerardo Sánchez Díaz (IIH-UMSNH), c1936 (izquierda). Fotografía propia, 2019 (derecha).

La Figura $\mathrm{N}^{\circ} 7$ debió ser tomada desde la escalinata que conduce a la cumbre de la isla de Janitzio, la cual está coronada por la emblemática estatua de José María Morelos. En este caso, la captura de la imagen en la revisitación se complicó al momento de intentar conseguir la misma posición que el fotógrafo original. La Figura $\mathrm{N}^{\circ} 8$, correspondiente a la toma actual, se realizó desde una azotea cercana a la escalinata, pues el exceso de toldos de plástico para cubrir de las inclemencias del tiempo a los comerciantes ambulantes, así como el levantamiento de arquitecturas en ambos costados del camino, dificultaron la ubicación original y la repetición de la fotografía. En la imagen histórica, se aprecia la zigzagueante escalinata empedrada. Posando para la foto se encuentra una mujer, con la clara intención de que la estatua de Morelos le sirva de vistoso fondo. En ese momento, la monumental escultura era una novedad -fue concluida justo en 1936 - que los visitantes podían visitar. Tanto los materiales del Morelos como de las escalinatas fueron llevados a la isla en embarcaciones, pues no había canteras en la pequeña Janitzio. A ambos costados del camino se observan pinos característicos de la región (Pinus michoacana) y sembrados como parte de la ornamentación paisajística. 
El contraste de la fotografía histórica con la imagen de 2019 es significativo. A simple vista, la escalinata no se aprecia, pues se oculta entre los edificios y los toldos de plástico. Las construcciones muestran una arquitectura improvisada e irregular, evidencia de un crecimiento espontáneo. Estas obras están orientadas al visitante, pues en la planta baja suelen instalarse restaurantes, servicios sanitarios y locales de objetos para el turismo, tales como artesanías, postales, llaveros, dulces o bebidas refrescantes. Los pisos superiores sirven de almacenes $\mathrm{u}$ oficinas para los locatarios, o bien se adaptan como viviendas temporales para los comerciantes. Los pinos ornamentales han desaparecido totalmente. En la isla, el manejo de residuos es deficiente y el exceso de visitantes genera una imagen poco pulcra. Incluso en la fotografía contemporánea, en la parte inferior se observa una acumulación de basura. Justo ahí se encuentra un perro que parece posar para la foto. A este propósito, es importante señalar la presencia abundante en la isla de perros en condición de calle.

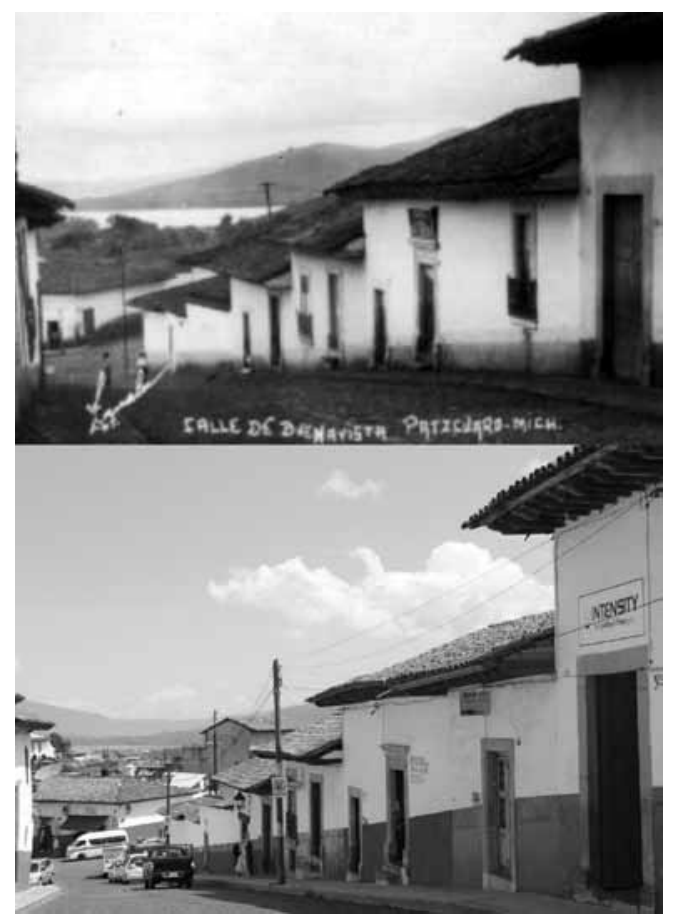

Figuras $N^{\circ} 9 y N^{\circ} 10$. Calle Buenavista y vista del lago, Pátzcuaro Fuentes: Archivo Gerardo Sánchez Díaz (IIH-UMSNH), c1930 (superior). Fotografía propia, 2019 (inferior). 
Las imágenes de las figuras $\mathrm{N}^{\circ} 9 \mathrm{y} \mathrm{N}^{\circ} 10$ fueron tomadas desde una posición elevada en el centro histórico de la ciudad de Pátzcuaro, teniendo como fondo el lago y el cerro Blanco. La ubicación corresponde a la calle Buenavista, establecida en una pendiente. En la fotografía histórica (Figura $\mathrm{N}^{\circ}$ ) se aprecian las casas con la arquitectura tradicional de la región: construcción de muros de adobe pintados de blanco y techos de tejas. También se observan los usos de aleros, ventanales y balcones de madera, como coadyuvantes urbanos de imagen típica en las riveras del lago. En los alrededores del lago de Pátzcuaro este tipo de viviendas han otorgado al paisaje una condición vernácula, pues son erigidas con materiales propios del área geográfica, mediante técnicas arquitectónicas transmitidas de generación en generación en las localidades tradicionales (Ettinger, 2010). La localidad cuenta con luz eléctrica, ya que son visibles los postes y los cables para su distribución. Las calles son empedradas y las baquetas son muy pequeñas, pues son prácticamente innecesarias. La movilidad se realiza mayoritariamente a pie.

En la fotografía contemporánea (Figura $\mathrm{N}^{\circ} 10$ ) se observa el esfuerzo municipal por preservar la idea de vivienda tradicional en Pátzcuaro, aunque con algunas adecuaciones. Los muros son de ladrillos y cemento. Su color sigue siendo blanco en su mayoría, pero con un metro de pintura roja a partir del suelo. Se conserva el uso de tejas en los techos, así como los balcones y ventanales de madera, aunque ahora se utiliza roca en los portales. Comparado con la imagen histórica, la ubicación de puertas y ventanas también se alteró. El uso de suelo ha cambiado, pues en su mayoría estos lugares son ahora de uso comercial, aprovechando que la calle Buenavista es una de las más transitadas, pues está a una corta distancia de la Basílica de la Virgen de la Salud, principal santuario religioso de la ciudad de Pátzcuaro. Se trata de una edificación colonial que atrae significativamente la presencia de visitantes durante todo el año. El crecimiento de las edificaciones impide que el lago, al fondo, se aprecie con mayor claridad, y el cerro Blanco ha desaparecido detrás de ellas. La presencia de vehículos también es un elemento constante en el paisaje urbano de Pátzcuaro, pues las vías de conectividad en la localidad privilegian ahora el tránsito vehicular antes que el peatonal. 



Figuras $N^{\circ} 11$ y $N^{\circ} 12$. Muelle en la isla de Janitzio

Fuentes: Archivo Gerardo Sánchez Díaz (IIH-UMSNH) ca1930 (superior). Fotografía propia, 2019 (inferior).

En la imagen histórica (Figura $\mathrm{N}^{\circ} 11$ ), aparece el muelle principal de isla de Janitzio, al nivel del lago de Pátzcuaro. Se observan, a la derecha inferior, unos pescadores trabajando sus redes. Son visibles también los pequeños muros de roca, levantados a manera de terrazas para la contención del agua. Las casas guardan la arquitectura tradicional con los techos de tejas. La fotografía es un vistazo al costumbrismo del paisaje lacustre y su entonces vocación pesquera tradicional. Ello resulta contrastante con la fotografía contemporánea (Figura $\mathrm{N}^{\circ} 12$ ). El muro del muelle ha sustituido a las delimitaciones de roca de las viviendas de los 
pescadores, y en el lago predominan las plantas flotadoras, resultantes del proceso de contaminación que ha impactado a todo el cuerpo lacustre. Ello dificulta el acceso a las embarcaciones, las cuales no son para la actividad pesquera sino para el traslado de pasajeros en calidad de turistas. En la isla han desaparecido las viviendas de arquitectura tradicional e imperan nuevamente los toldos o lonas para cubrir los comercios. Esto último es la única actividad económica, pues la pesca en el lugar no es ya una opción. Las especies nativas rentables, en particular el pez blanco, disminuyeron su presencia en las aguas lacustres por la contaminación hídrica y por la presencia dominante de especies exóticas, como la tilapia y la carpa, económicamente menos redituables.
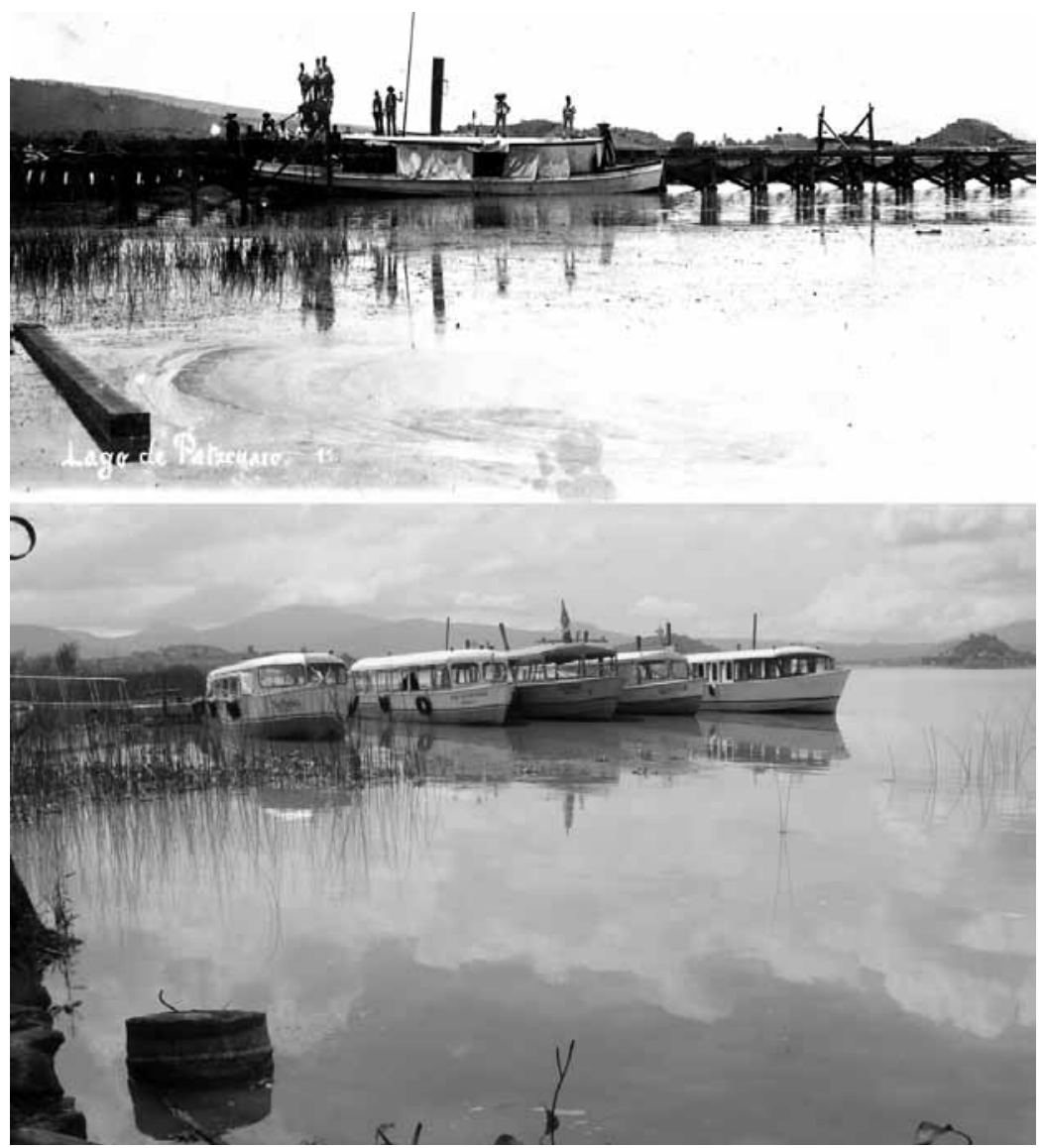

Figuras $N^{\circ} 13$ y $N^{\circ} 14$. Muelle de Ucazanastacua, lago de Pátzcuaro

Fuentes: Archivo Gerardo Sánchez Díaz (IIH-UMSNH) ca1930 (superior). Fotografía propia, 2019 (inferior). 
En la imagen histórica (Figura $\mathrm{N}^{\circ} 13$ ) se puede observar, en un plano central, el muelle y una embarcación. Por sus características - alargada, con toldos protectores del clima, techada-, puede saberse que no está destinada a la pesca, sino para el transporte de pasajeros de las riberas del lago a las islas. Posando para la toma, se encuentran una docena de personas; algunas de ellas usan sombreros típicos de la región. En el lago se aprecian algunos juncos. Las islas están al fondo. De derecha a izquierda, primero aparece Tecuena, visiblemente más alta, sin edificaciones arquitectónicas. A su costado, apenas perceptible detrás del muelle, está Janitzio.

La fotografía contemporánea (Figura $\mathrm{N}^{\circ} 14$ ), es capturada desde uno de los costados del muelle de Ucazanastacua, visiblemente más pequeño que antes. Desde este muelle, la afluencia de visitantes es menor, comparada con la de otros embarcaderos del lago que pueden encontrarse en las riberas de Pátzcuaro. Aparecen cinco embarcaciones destinadas a la actividad turística. Su diseño es más elaborado que la embarcación tradicional. Al fondo, las islas presentan algunos cambios. Tecuena, a la derecha, muestra una aparente mayor altitud. Ello se debe al descenso del nivel del agua, lo que propicia que las islas ganen superficie terrestre. A la izquierda, Janitzio muestra ya construcciones estructuras urbanas hasta la cúspide del cerro coronado por la estatua de Morelos. En el lago, como en casi cualquier imagen, se observa una cantidad considerable de plantas acuáticas flotantes - constante indicador de contaminación lacustre - rodeando a los juncos. Cerca del muelle se observa también basura, sobre todo en la parte inferior izquierda. Esto muestra que, a pesar de que el turismo es la principal actividad económica de las localidades de las riberas de lago y sus islas, no hay una preocupación concreta o política ambiental destinada al manejo de residuos, consecuencia de la presencia numerosa y constante de visitantes. 


\section{Discusión}



Figura $N^{\circ} 15$. Ubicación de los lugares revisitados Fuente: Elaboración propia.

Con el ejercicio de revisitación geográfica, mediante el uso de fotografías comparadas, se trató de mostrar, de manera general, los vistazos a los referentes topográficos e icónicos en el lago de Pátzcuaro, a partir de su consideración como un paisaje cultural (Figura $\mathrm{N}^{\circ} 15$ ). Si bien es cierto que esto es solo una aproximación que, para mayor detalle, tendría que incluir una combinación dinámica de otras fuentes de información histórica cotejables en campo - tales como cartografías, relatos de viaje o pinturas-, es ejemplificadora de los rasgos culturales impresos en el paisaje y de las sucesivas reintepretaciones o adecuaciones sociales que se manifiestan en él. En el caso particular del lago, la revisitación en campo y el uso de fotografías del antes y el después, permite una aproximación in situ a la historia cultural de su entorno.

Lo que la revisitación al lago de Pátzcuaro muestra es la reafirmación visual del tránsito de un ambiente rural y costumbrista, cuya actividad principal era la pesca, a una dinámica regional dependiente fundamentalmente del turismo que, en la actualidad, no goza de los beneficios económicos de antaño. Como se ha señalado, la promoción 
gubernamental federal se reorientó hacia los destinos de playa desde la década los cuarenta del siglo pasado, y se encaminó a la atracción de visitantes internacionales. A pesar de este inconveniente, el turismo regional en Pátzcuaro sigue aprovechando los íconos topológicos del lugar, erigidos en décadas anteriores. Sobre todo, destaca la posición y promoción de la isla de Janitzio y la emblemática estatua de Morelos.

La infraestructura y los elementos icónicos en el paisaje, todavía perceptibles en el entorno actual, guardan algo del pretendido resplandor de las décadas de los veinte y de los treinta de la centuria pasada.

Por otro lado, también es visible, y más evidente, el deterioro de la actividad original del lago - la pesca-, y la poca atención gubernamental respecto de la adecuada planeación del proyecto original: promover el paisaje lacustre, lo que implica un manejo ambiental adecuado. Resulta contradictorio que un lugar diseñado para la admiración escénica y la apreciación de la relación humano-naturaleza, conlleve hoy vistazos a la saturación comercial de las islas, la acumulación de basura fuera de contenedores, la contaminación del lago y la desaparición de vegetación, entre otros factores.

\section{Conclusiones}

El ejercicio realizado en el contexto lacustre de Pátzcuaro nos permitió ponderar dos aspectos principales. En primer lugar, consideramos pertinente resaltar la importancia del trabajo de campo como un elemento clave para el aprendizaje situado en torno al paisaje cultural. Debido a las formas actuales de enseñanza geográfica y a los medios con los que se cuenta, pareciera que la experiencia in situ es algo meramente complementario o prescindible. Los estudiantes tienen acceso inmediato a la información de casi cualquier lugar en el mundo gracias a la poderosa herramienta de internet y sus ilimitados datos: imágenes áreas en todas las escalas, fotografías con diferentes temporalidades, mapas antiguos y contemporáneos, monografías informativas sobre las condiciones biofísicas y socioculturales, bibliografías y hemerografías, videos y documentales, opiniones y debates a través de chats, solo por mencionar los más recurrentes. A través de la plataforma Google Earth, incluso, es posible ubicarse virtualmente en casi cualquier parte del mundo y obtener la vista a nivel de tierra. No obstante, estar en campo permite una inmersión en el paisaje, derivada del estar ahí, y 
se vuelve una experiencia personal que no tiene réplica en internet o en el aula.

En segundo lugar, y derivado de lo anterior, la revisitación geográfica y su valoración a través de fotografías repetidas es una forma de aproximación al paisaje a través de las distintas miradas que se apropian culturalmente de él, y en diferentes escalas de tiempos. Permite, de manera relativamente sencilla, comprender cómo el entorno se transforma y se reinterpreta históricamente mediante el reconocimiento de los cambios geográficos o ambientales y de los íconos topográficos que se han plasmado en el lugar. Es decir, no solo visualiza las transformaciones paisajísticas, también genera conciencia en torno a los cambios temporales. En otras palabras, es una manera directa y aplicada de enseñar las relaciones intrínsecas entre la geografía y la historia.

\section{Referencias bibliográficas}

a) Artículos y capítulos de libros

Alonso-Eguía, P. y S. Vargas (2014). "Análisis ecosistémico de la introducción de especies exóticas en el lago de Pátzcuaro", en L. Pfeng (ed.), Distribución de especies invasoras acuáticas: casos de estudio, México: Secretaría de Medio Ambiente y Recursos Naturales, pp. 337-358.

Alvarado-Sizzo, I y A. López-López. (2018). “Turismo, patrimonio y representaciones espaciales. Introducción a una reflexión necesaria", en I. Alvarado-Sizzo y A. López-López (coords.), Turismo, patrimonio y representaciones espaciales, Tenerife: Pasos, pp. 15-24.

Barrasa, S. (2013). "Valoración de la calidad estética de los paisajes de La Habana (Cuba) con métodos de participación social", en Estudios Geográficos, vol. 58, № 274, pp. 45-66.

Bass, J. O. y S. Brady. (2011). "The changing anatomy of Mexican towns: Repeat study and Stanislawski's Michoacan", en The Pennsylvania Geographer, vol. 1, No 4, pp. 18-41.

Brady, S. (2009). "Revisiting a Honduran landscape described by Robert West: An experiment in repeat geography", en Journal of Latin American Geography, vol. 8, № 1, pp. 7-27.

Butler, D. R. (1994). "Repeat Photography as a tool for emphasizing movement in Physical Geography", en Journal of Geography, vol. 93, No 3, pp. 141-151. 
Byers, A. C. (2017). “Una evaluación cualitativa de la pérdida actual de glaciares en la Cordillera Blanca, Perú, usando fotografía repetitiva", en Revista de glaciares y ecosistemas de montaña, $\mathrm{N}^{\circ}$ 2, pp. 31-40.

Fernández-Christlieb, F. (2006). "La geografía cultural”, en D. Hiernaux y A. Lindón (coords.), Tratado de Geografía humana, Barcelona: Anthropos/UAM-Iztapalapa, pp. 220-253.

González-Jácome, A. (2005). "Reconsiderando a Carl Sauer”, en Perspectivas latinoamericanas, № 2, pp. 13-27.

Jolly, J. (2015). “Vista del lago de Pátzcuaro: paisaje, turismo y la construcción de la nación", en L. Noelle y D. Wood (eds.), Estética del paisaje en las Américas, México: Instituto de Investigaciones Estéticas UNAM, pp. 231-247.

Jolly, J. (2018). Creating Pátzcuaro, Creating México. Art, tourism, and nation building under Lázaro Cárdenas. Austin: University of Texas Press.

Laylander, (2016). “The Berkeley Geographers and Baja California's Prehistory", en Journal of California and Great Basin Anthropology, vol. 36, № 1, pp. 128-137.

Lindón, A. (2015). "Del cronotopo fundacional a la construcción socio-espacial del territorio vallechalquense", en A. Lindón y C. Mendoza (coords.), La periferia metropolitana: entre la ciudad prometida y un lugar para habitar la Ciudad de México, México: Gedisa/UAM-I, pp. 115-150.

Lira, M. G., P. C. Segundo y P. S. Urquijo. (2019). “Revisitación geográfica en tres localidades de Michoacán. Las observaciones de Dan Stanislawski siete décadas después", en P. S. Urquijo y A. Vieyra (coords.), Geografía y ambiente en escala local, Morelia: Centro de Investigaciones en Geografía Ambiental UNAM, pp. 59-78.

Massey, D. (1996). “A global sense of place”, en S. Daniel \& R. Lee (eds.), Exploring human geography, London: Arnold, pp. 237-245.

Mathewson, K. (2010). "Geographers and the theory and practice of return fieldwork", en Journal of Cultural Geography, vol. 27, No 3, pp. 353-365.

Meyer, J. L. y Y. Youngs, (2018). "Historical landscape change in Yelloswstone National Park: Demonstrating the value of intensive field observation and repeat photography", en Geographical Review, vol. 108, № 3, pp. 387-409. 
Novo, G., M. Osorio, J. Torres y E. Esquivel. (2013). "Viajes, actuantes, escenario e interacciones. Un análisis de la publicidad turística de los destinos a partir de semánticas visuales", en Investigaciones turísticas, № 6, pp. 27-46.

Rakic, T. y D. Chambers, (2012). "Introducing visual methods to tourism studies", en T. Rakic y D. Chambers (eds.), An Introduction to visual research methods in tourism, London: Routledge, pp. 3-14.

Rose-Redwood, R. (2008). "Genealogies of the grid: Revisiting Stanislawski's search for the origin of the grid-pattern town", en The Geographical Review, vol. 98, № 1, pp. 42-58.

Rzedowski, J., S. Zamudio, G. Calderón y A. Paizanni. (2014). “El bosque tropical caducifolio en la cuenca Lacustre de Pátzcuaro (Michoacán, México)", en Flora del Bajío y de regiones adyacentes. Fascículo Complementario del Instituto de Ecología A. C., № 29, pp. 1-18.

Urquijo, P. S. (2020). "Paisaje cultural: un enfoque pertinente", en P. S. Urquijo y A. F. Boni (coords.), Huellas en el paisaje. Geografía, historia y ambiente en las Américas, Morelia: Centro de Investigaciones en Geografía Ambiental.

Urquijo, P. S., P. C. Segundo y G. Bocco. (2020). “Geografía latinoamericanista en México: Balance histórico a partir de la Escuela de Berkeley", en Journal of Latin American Geography, vol. 19, No 1, pp. 1-17.

Walker, J. y J. Leib, (2002). "Revisiting the Topia Road: Walking in the Footspets of West and Parsons", en Geographical Review, vol. 92, № 4, pp. 555-581.

Works, M. A. \& K. S. Hadley, (2000). “Hace cincuenta años: Repeat photography and landscape change in the Sierra Purépecha of Michoacán, México", en Yearbook Conference of Latin Americanist Geographers, № 26, pp. 139-155.

\section{b) Libros}

Ettinger, C. R. (2010). La transformación de la vivienda vernácula en Michoacán. Materialidad, espacio y representación. Morelia: Universidad Michoacana/El Colegio de Michoacán.

Sarlo, B. (2006). Tiempo pasado. Cultura de la memoria y giro subjetivo, una discusión. Buenos Aires: Siglo XXI. 
Stanislawski, D. (1950). The anatomy of eleven towns in Michoacan. Austin: University of Texas Press.

Tuan, Y. F. (2001). Space and place. The perspective of experience. Minneapolis: Minnesota University Press.

Urry, J. (1990). Tourist gaze: Leisure and travel in contemporary societies. London: Sage.

West, R. (1948). Cultural geography of modern Tarascan area. Washington D.C: Smithsonian Institution. 